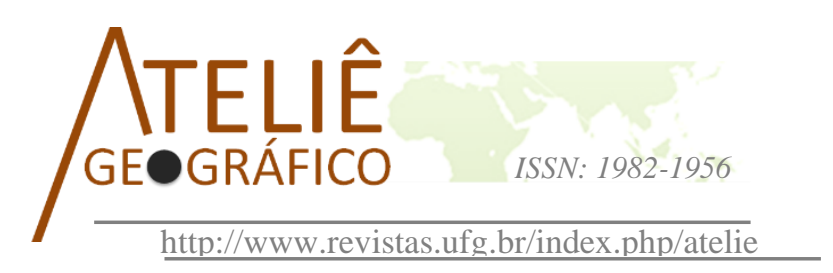

\title{
A territorialização da rede global extrativa do nióbio em Goiás, Brasil
}

\author{
The territorialization of the niobium global extractive \\ network in Goiás, Brazil
}

\section{La territorialización de la red extractiva global de niobio en Goiás, Brasil}

\author{
Ricardo Junior de Assis Fernandes Gonçalves \\ Universidade Estadual de Goiás \\ ricardo.goncalves@ueg.br
}

Bruno Milanez

Universidade Federal de Juiz de Fora

bruno.milanez@ufjf.edu.br

\begin{abstract}
Resumo
O objetivo da presente pesquisa é interpretar a territorialização da Rede Global Extrativa de nióbio em Goiás, Brasil. A metodologia conta com levantamento de dados secundários e informações qualitativas e quantitativas. A primeira parte da pesquisa apresenta resultados que abordam a mineração de nióbio no Brasil, com foco na caracterização desse metal, principais aplicações em diferentes setores produtivos, localização das maiores reservas e minas em operação. Destacam-se as principais empresas produtoras e suas estratégias corporativas, a evolução da produção de ferronióbio, mercado e preços. Na segunda parte, demonstra-se a participação da mineração, com base nos empreendimentos de nióbio, no processo de integração do território goiano nas redes globais extrativas. As considerações finais sintetizam os resultados centrais expostos nas seções anteriores e sublinham as possíveis contribuições da pesquisa no campo das investigações críticas sobre o modelo de mineração no Brasil. Palavras-Chave: Mineração. Nióbio. Rede Global de Produção. Goiás.
\end{abstract}

\footnotetext{
Abstract

This research aims at interpreting the territorialization of the Niobium Global Extractive Network in Goiás state, Brazil. The methodology is based on secondary data and qualitative and quantitative information. The first part of the article describes the niobium extraction in Brazil, characterizing the metal's properties, its main applications in different economic sectors, location of the major reserves, and operating mines. It also highlights the leading extractive corporations, their market strategies, and the evolution of iron-niobium production, market, and prices. In the
} 
second part, the text describes the participation of niobium mining corporations in the integration of Goiás state in the global extractive network. The final section summarizes the main results and underlines possible contributions for future critical research on the Brazilian mining model.

Keywords: Mining. Niobium. Global Production Network. Goiás.

\begin{abstract}
Resumen
El objetivo de la presente investigación es interpretar la territorialización de la Red Extractiva global de niobio en Goiás, Brasil. La metodología incluye la recolección de datos secundarios e información cualitativa y cuantitativa. La primera parte de la investigación presenta resultados que abordan la minería de niobio en Brasil, centrándose en la caracterización de este metal, las principales aplicaciones en diferentes sectores productivos, la ubicación de las mayores reservas y minas en operación. Destacamos las principales empresas productoras y sus estrategias corporativas, la evolución de la producción, el mercado y los precios del hierro de niobio. En la segunda parte, la participación de la minería, basada en proyectos de niobio, se demuestra en el proceso de integración del territorio goiano en las redes extractivas mundiales. Las consideraciones finales resumen los resultados centrales presentados en las secciones anteriores y subrayan las posibles contribuciones de la investigación en el campo de las investigaciones críticas sobre el modelo de minero en Brasil.
\end{abstract}

Palabras-Clave: Minería. Niobio. Red Mundial de Producción. Goiás.

\title{
Introdução
}

Desde o início do século XXI presenciam-se as implicações econômicas, políticas e ambientais do "modelo rentista-neoextrativista" (CARVALHO et al., 2018) no Brasil, estruturado por setores extrativos como a mineração. Em 2017 o valor da Produção Mineral Brasileira (PMB) foi de US\$ 32,0 bilhões, enquanto o valor das exportações de bens minerais somou US\$ FOB 28,3 bilhões, sendo o minério de ferro, ouro, cobre e ferronióbio os quatro principais. Com efeito, Minas Gerais, Pará, Goiás, São Paulo e Bahia foram os principais estados minerados, conforme a receita econômica gerada (IBRAM, 2018).

O setor extrativo mineral está presente em praticamente todos os estados brasileiros. Nesse sentido, destaca-se a posição de Goiás na escala da extração mineral brasileira como território da megamineração de níquel, fosfato, bauxita, cobre, amianto, ouro e nióbio. Com ênfase no nióbio, o presente estudo baseia-se no modelo das Redes Globais de Produção ${ }^{1}$ (HENDERSON, 2002; HESS, 2004; SANTOS e MILANEZ, 2015) para descrever a territorialização e o posicionamento da empresa CMOC International Brasil, subsidiária da China Molybdenum Co., Ltd., em Goiás.

\footnotetext{
${ }^{1}$ Apesar do termo consagrado na literatura ser Rede Global de Produção, aqui nos referimos à Rede Global Extrativa apenas para garantir uma maior precisão nos termos, e devido às características particulares do setor extrativo mineral que o diferencia consideravelmente da indústria manufatureira, para qual o modelo RGP foi originalmente concebido. Apesar dessa mudança na nomenclatura, as categorias e conceitos utilizados são essencialmente os mesmos da RGP, conforme discutido em Milanez et al. (2018).
} 
Desse modo, o objetivo desta pesquisa é descrever a estrutura da Rede Global Extrativa do nióbio e interpretar a territorialização desta rede em Goiás. A metodologia conta com revisão bibliográfica, levantamento de dados e informações qualitativas e quantitativas sistematizadas em gráficos e mapas. Avalia-se a diferença no enraizamento em rede e na estratégia de mercado da CMOC, quando comparada com a Companhia Brasileira de Metalurgia e Mineração (CBMM). A partir dessa avaliação, identifica-se a concentração da rede, tanto do ponto de vista de oferta e demanda, bem como as restrições ao eventual desenvolvimento das atividades de extração e beneficiamento primário no Brasil. Além disso, distinguem-se três elementos particulares dessa rede: a crescente dependência material da transição tecnológica para a economia de baixo carbono, o crescimento da influência chinesa na rede do nióbio e o risco de queda brusca de preço do metal no caso de uma elevação abrupta de oferta.

Além desta introdução, o texto está dividido em duas partes principais e as considerações finais. A primeira descreve a inserção do Brasil na cadeia extrativa do nióbio. Para tanto, especificam-se os usos e características gerais deste metal, analisa-se o posicionamento do Brasil dentro da rede e comenta-se, como base de comparação, a estratégia de mercado e enraizamento em rede da CBMM. Após essa contextualização, na segunda seção apresenta-se a participação do setor extrativo mineral na economia de Goiás e, posteriormente, avalia-se o processo de territorialização da extração de nióbio no estado. $\mathrm{Na}$ parte final, não apenas consolidam-se as contribuições da pesquisa no campo das investigações críticas sobre o modelo de mineração no Brasil, como ainda se destacam aspectos a serem aprofundados em pesquisas futuras.

\section{A integração do Brasil na Rede Global Extrativa do nióbio}

Conforme informações da Agência Nacional de Mineração (ANM, 2017), as reservas de nióbio conhecidas no Brasil somam aproximadamente 842,4 milhões de toneladas. Outros países contêm depósitos do metal, tais como Canadá, Austrália, Estados Unidos, Angola, Rússia, Arábia Saudita, Finlândia, Nigéria e Etiópia. Cerca de 527 carbonatitos identificados no mundo podem hospedar nióbio; desse total, 85 depósitos já apresentam estudos e classificação da ocorrência mineral. Dentre eles, nove produzem nióbio (CBMM, Brasil; Magris Resources, Canadá; CMOC, Brasil [2 depósitos]; Mineração Taboca, Brasil; AMG Mineração, Brasil; Lovozero, Rússia [2 depósitos]; Bayan Obo, Mongólia Interior, China) e outros quatro projetos se encontram em estágio de implantação avançado (Dubbo, na Austrália; Panda Hill, na Tanzânia; Elk Creek, nos Estados Unidos; e Kringlerne, na Groelândia) (CBMM, 2019; IBRAM, 2019).

O Brasil está integrado na Rede Global Extrativa do nióbio como país responsável por cerca de $84 \%$ da produção do metal no mundo, seguido pelo Canadá, que explota o nióbio na província de Quebec (CBMM, 2019; IBRAM, 2019). Desde o início da década de 1980 o nióbio brasileiro não é exportado sem antes ser transformado em produtos semi-acabados. Cerca de $90 \%$ do nióbio extraído anualmente no Brasil é transformado em ferro-nióbio (liga metálica composta por $65 \%$ de nióbio e $35 \%$ de ferro); 
apenas $10 \%$ é exportado como bens de maior intensidade tecnológica, como as ligas de grau vácuo, o nióbio metálico e os óxidos de nióbio (CBMM, 2019).

O principal produto de exportação derivado do nióbio brasileiro é a liga de ferronióbio. Essa liga é consumida por siderúrgicas na produção de aços microligados de elevada resistência. Segundo a CBMM (2018), aproximadamente 10\% da produção mundial de aço usa o nióbio na forma de ferro-nióbio. As ligas de grau vácuo, por sua vez, têm utilidade na produção de superligas de aço a base de níquel. Ainda, o nióbio metálico, cujos lingotes possuem concentração de $99 \%$ de nióbio, tem propriedades supercondutoras e grande resistência à corrosão e é aplicado em aparelhos de ressonância magnética, tomógrafos e aceleradores de partículas. Por fim, os óxidos de nióbio são usados em aplicações especiais de grande valor tecnológico, como lentes de telescópios, baterias de carros elétricos e catalizadores (VASCONCELOS, 2018; PEREIRA JÚNIOR, 2010; CBMM, 2019).

Apesar da utilização do nióbio em diferentes finalidades, as quantidades demandadas pelo mercado tendem a ser, em termos gerais, pequenas. Assim, considerando a concentração das reservas no Brasil e a situação de baixa competição, as empresas do setor tenderiam, historicamente, a manter um tênue equilíbrio entre oferta e demanda para garantir um preço e uma lucratividade compatíveis com suas expectativas.

A produção brasileira de ferro-nióbio apresentou um crescimento de $162,8 \%$ entre 2005 e 2018 (ANM, 2009, 2018). O consumo brasileiro de ferro-nióbio é relativamente baixo, em média 4 mil toneladas nos últimos anos, concentrado nas demandas de empresas metalúrgicas nacionais localizadas em estados como Minas Gerais, Espírito Santo, Rio de Janeiro, São Paulo e Pará (ANM, 2017). Esse fato expõe a dependência das empresas mineradoras em relação à demanda global.

Conforme apresentado na Figura 01, as exportações brasileiras de ferro-nióbio apresentaram crescimento de aproximadamente 84,8\% entre 2005 e 2018. Na interpretação do comportamento da exportação no decorrer desses anos, apenas 2009 evidenciou queda na quantidade total exportada. Esse fato esteve, provavelmente, conectado à crise financeira de 2008. Destarte, a crise que impactou as principais economias mundiais também afetou negativamente as exportações brasileiras da liga ferro-nióbio.

Nesse período, o Brasil vendeu ferro-nióbio para um média de vinte e cinco países. No entanto, apenas cinco se destacaram como os principais compradores: Países Baixos, China, Estados Unidos, Japão e Cingapura. Durante os quatorze anos, das 960,6 mil toneladas de ferro-nióbio exportadas, somente os cinco países enfatizados compraram 840,5 mil toneladas, $87,4 \%$ do total (MDIC, 2019). 


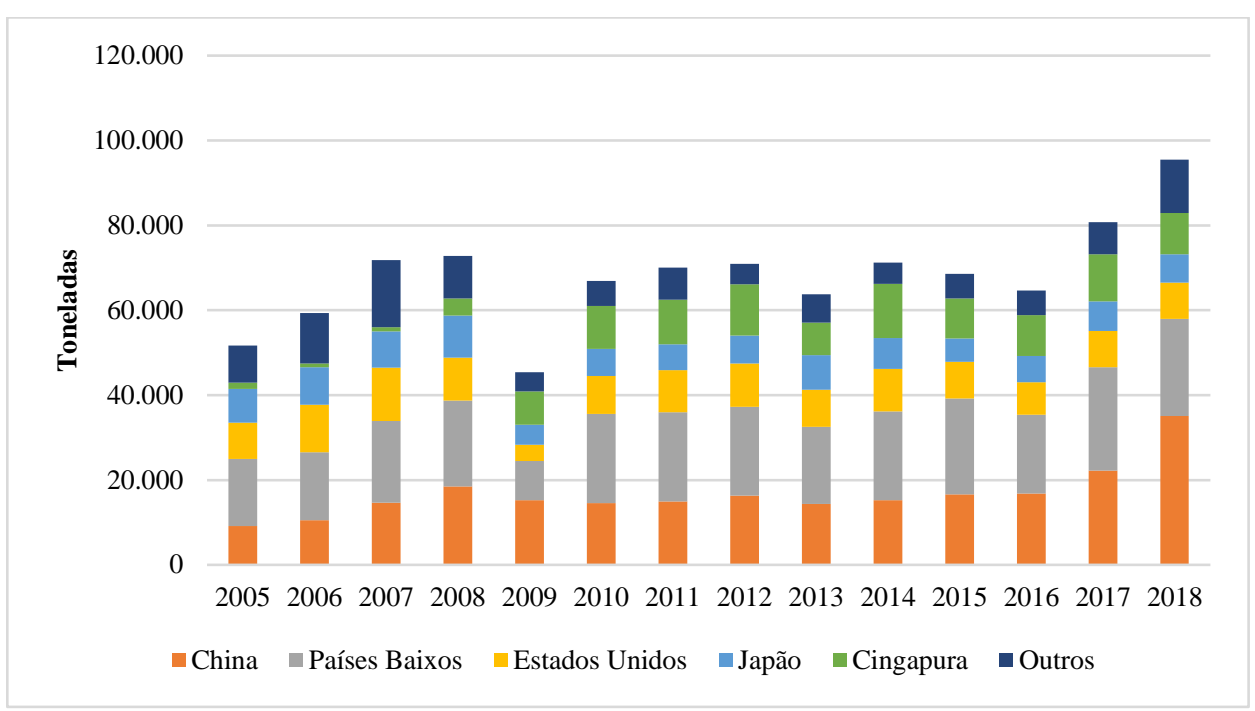

Figura 01: Evolução do volume de ferro-nióbio exportado e principais importadores globais - 2005 a 2018.

Fonte: MDIC, 2019. Elaboração: GONÇALVES, R. J. A. F.; MILANEZ, B., 2019.

A análise dos dados e informações amplia a compreensão da Rede Global Extrativa do nióbio ao revelar o lastro geopolítico da participação de alguns países e regiões. Primeiro, destaca-se a presença dos Países Baixos, Estados Unidos e Japão na rede global. Esses três países representaram médias de importações estáveis no período analisado - os Países Baixos uma média de 20 mil toneladas por ano; os Estados Unidos, 8 mil toneladas; e o Japão 6,5 mil toneladas. A presença dos Países Baixos não tem relação direta com a absorção interna do ferro-nióbio, mas sim, à presença do porto de Roterdã, maior porto marítimo da Europa.

Outro aspecto revelado pela Figura 01 é o crescimento da participação do mercado asiático na rede do ferro-nióbio. Além do Japão, países como China, Coreia do Sul, Índia e Cingapura (que teve um crescimento significativo a partir de 2008) avolumaram as compras da liga. Desse modo, entre eles, a China se destaca com um aumento em suas importações de $283,7 \%$ entre 2005 a 2018. Só esse país comprou 24,3\% do total de ferro-nióbio exportado pelo Brasil no decurso dos quatorze anos.

A análise da participação chinesa no mercado de ferro-nióbio sublinha dois momentos de significativo crescimento, de 2005 a 2008 e de 2016 a 2018. No primeiro, as importações foram de 9,1 mil toneladas em 2005 e 18,4 mil toneladas em 2008, um aumento de $101,9 \%$. Após 2009, manteve-se um equilíbrio nas importações chinesas até por volta de 2016, quando houve um crescimento de 16,7 mil toneladas para 35 mil toneladas em 2018, acréscimo de 109,5\%. O aumento do consumo chinês pode ser associado à mudança da estrutura acionária das empresas que atuam no Brasil, como será discutido em maiores detalhes nas seções seguintes. 
Sendo assim, pontua-se que o comportamento do mercado global de ferro-nióbio, com aumento recente da presença da China, influenciou no preço do nióbio no período entre 2005 e 2018, conforme apresentado na Figura 02.

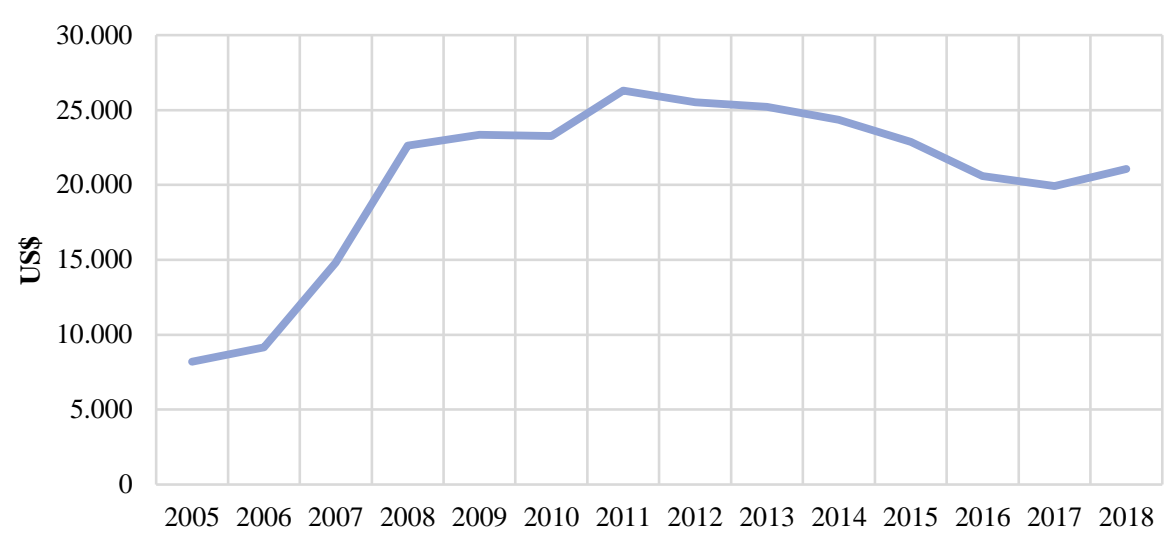

Figura 02: Evolução do preço nominal (em US\$) da tonelada de ferro-nióbio - 2005 a 2018. Fonte: MDIC, 2019. Elaboração: GONÇALVES, R. J. A. F.; MILANEZ, B., 2019.

Pereira Junior (2010) explica que os preços do ferro-nióbio têm relação com o fato da comercialização dos produtos de nióbio ser realizada diretamente pelas empresas produtoras nos mercados consumidores e não por intermédio das bolsas de commodities como a London Metal Exchange e o New York Commodity Exchange. A estipulação dos preços tem relação com o teor de nióbio contido nas ligas e os valores praticados pela CBMM, que, historicamente, foram adotados como referência para as demais companhias (CBMM, 2019).

Ainda acerca do preço do ferro-nióbio, Pereira Junior (2010) pontua que ele depende do desempenho da siderurgia e dos investimentos em megaprojetos de infraestruturas, que demandam aços reforçados pela liga, como gasodutos, refinarias, plataformas de exploração de petróleo, pontes e edifícios. Por consequência, destaca-se a configuração geopolítica internacional representada por novos arranjos como o crescimento econômico dos países asiáticos nos últimos anos, com o protagonismo da China.

Sendo assim, na comparação entre as Figuras 1 e 2, pode ser identificado um período de consumo e de preços crescentes no período 2005 - 2008. Com a crise do mercado financeiro, a quantidade exportada caiu significativamente, apesar de certa estabilidade dos preços (provavelmente associado a contratos de venda definidos anteriormente, como é comum em alguns segmentos de metais estratégicos). No período 2009 - 2013, houve uma leve variação em quantidade e preço, possivelmente relacionada aos ajustes de demanda no pós-crise. Entre 2014 e 2016 verificou-se uma curva decrescente na demanda, que somente se inverteu em 2017, com o aumento da demanda 
chinesa. O preço, por outro lado, demonstrou alguma recuperação um ano mais tarde, o que sugere, por sua vez, a instabilidade do equilíbrio entre preço e quantidade exportada (MDIC, 2019).

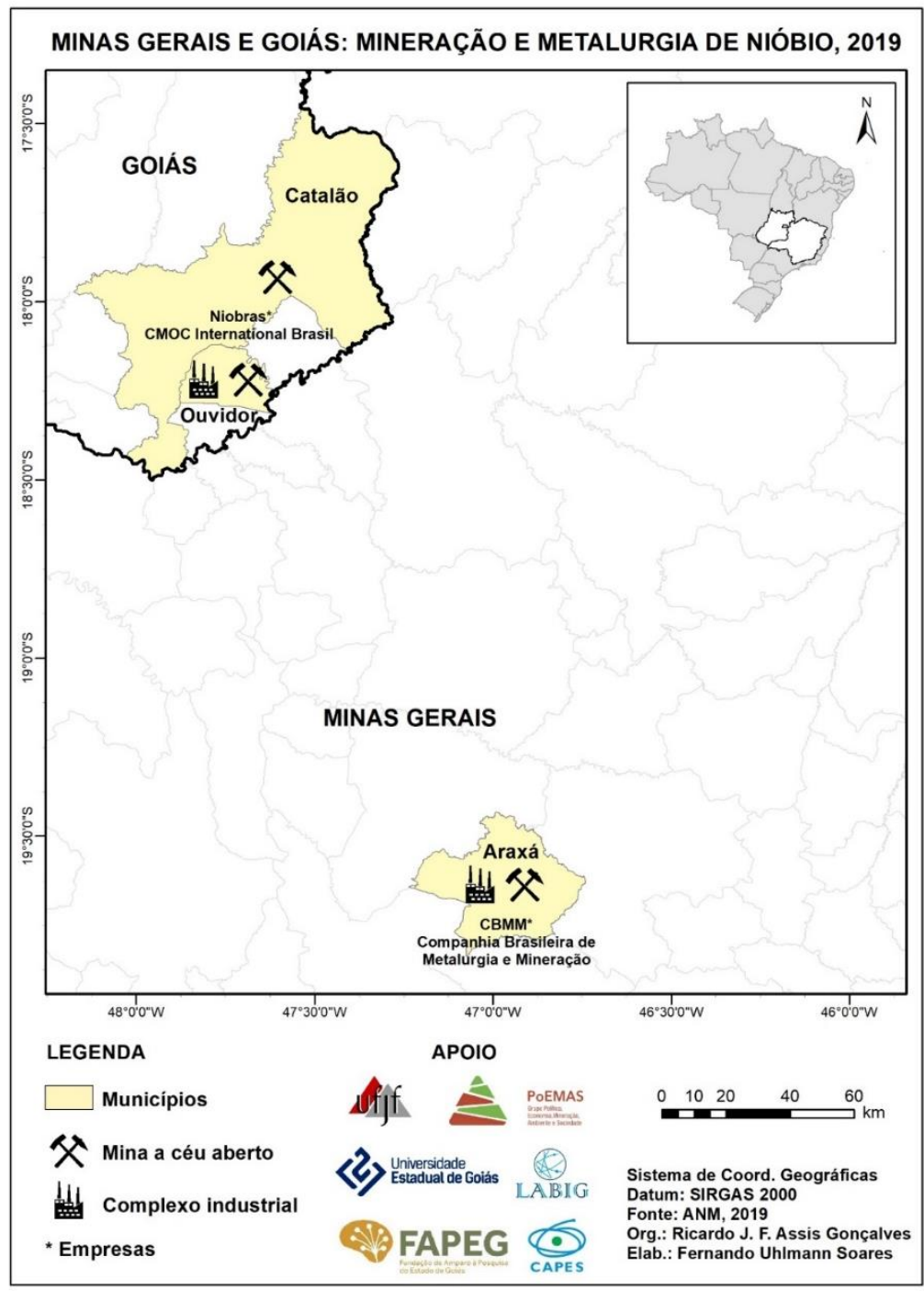

Figura 03: Localização geográfica dos dois principais megaempreendimentos de mineração e metalurgia de nióbio no Brasil.

A extração e a metalurgia de nióbio no Brasil estão concentradas em dois grandes projetos localizados em Goiás e Minas Gerais (Figura 03), operados respectivamente por 
CMOC/Niobras e CBMM. São esses megaempreendimentos que respondem por quase a totalidade do ferro-nióbio produzido no Brasil (cerca de 90\%). O restante da produção concentra-se em projetos de menor porte, como a Mineração Taboca S. A., e a Metalmig Ltda., que operam no Amazonas e Rondônia, respectivamente (ANM, 2018).

Em Goiás, a chinesa CMOC International Brasil controla a empresa Niobras. A principal fonte de explotação mineral em jazidas de pirocloro (uma das principais fontes minerais de nióbio) em Catalão é a Mina Boa Vista, que opera com lavra a céu aberto (SILVA et. al., 2017). O mineral extraído na mina é transportado em caminhões para a usina de beneficiamento em Ouvidor, a cerca de $23 \mathrm{~km}$ da mina, onde são produzidas as ligas de ferro-nióbio para comercialização no mercado internacional (CMOC, 2019).

Em Minas Gerais, no município de Araxá, o Complexo do Barreiro é composto por minas a céu aberto e a unidade industrial da CBMM. O nióbio é extraído de uma mina da CBMM e de outra da Companhia de Desenvolvimento Econômico de Minas Gerais (CODEMIG). Com o objetivo de gerenciar as jazidas de nióbio, criou-se em 1972 a Companhia Mineradora do Pirocloro de Araxá (COMIPA), uma joint venture entre a CBMM e CODEMIG. O contrato firmado entre as empresas define o controle compartilhado da COMIPA e a extração paritária do minério nas minas. A CBMM se destaca no mercado por seu investimento no desenvolvimento de tecnologias de processamento e de aplicação dos produtos industrializados (ALMG, 2019; CBMM, 2019; G1, 2019).

Com uma participação bastante inferior, pode ser mencionada ainda a empresa Mineração Taboca, controlada pela peruana Minsur, que possui uma unidade de mineração e metalurgia em Pitinga, no município de Presidente Figueiredo (AM). Diferente das outras unidades, ela extrai nióbio a partir de reservas de columbita-tantalita. Por fim, a Metalmig opera em Itapuão do Oeste (RO), onde também extrai columbita-tantalita (ANM, 2019).

A demanda por nióbio no mercado internacional teve impacto na dinâmica da rede extrativa no Brasil. Do ponto de vista territorial, as empresas produtoras ampliaram as minas existentes, ou abriram novas minas, quando necessário. Elas ainda investiram em projetos de expansão de unidades industriais, ampliação de barragens de rejeitos e pilhas de estéril. Ainda, houve o surgimento de novos projetos de investimentos para aumentar a produção. Nos principais estados produtores, o crescimento do valor das operações minerais de nióbio foi considerável. Em Goiás, esses valores se elevaram de R \$24,7 milhões em 2005 para 369,3 milhões em 2018, um aumento de 1.391\%. Em Minas Gerais, esse valor subiu de R \$ 50,8 milhões em 2005 para R \$ 336,9 milhões em 2018, um aumento de $563 \%$ (ANM, 2019).

Devido a essa dinâmica, torna-se imperativo analisar o processo de territorialização da CMOC/Niobrás em Goiás. Antes dessa avaliação, porém, será apresentada uma breve análise da estruturação da CBMM, de forma a servir como referência na análise da empresa chinesa. 


\section{O posicionamento da Companhia Brasileira de Metalurgia e Mineração (CBMM)}

A CBMM foi fundada em 1955 e, nos anos seguintes, se consolidou como a maior fornecedora global de produtos de nióbio. Ela é controlada desde 1965 pela família Moreira Salles (CBMM, 2019). Em 2011 um consórcio formado pela empresa estatal chinesa de investimentos Citic Group Corporation Ltd., e pelas produtoras de aço inoxidável Taiyuan Iron \& Steel Corporation (TISCO) e Baosteel, compraram 15\% da CBMM, por cerca de US\$ 1,9 bilhão (STELZER JR., 2016; CMOC, 2019). No mesmo ano, um grupo de companhias japonesas e sul coreanas compraram outros $15 \%$ da CBMM (CBMM, 2018).

Em 2019, além da sede, mina, unidades de produção e centro de tecnologia localizados em Araxá, e um escritório em São Paulo (SP), a CBMM possuía subsidiárias em diferentes países, como a CBMM Europe BV, em Amsterdã, na Holanda; CBMM Ásia Pte. Ltda., em Cingapura; CBMM North America Inc., nos Estados Unidos; e a subsidiária CBMM Technology Suisse, na Suíça, dedicada à gestão de projetos de desenvolvimento e aplicação do nióbio em novos produtos. A empresa detém ainda os distribuidores CITIC Metal Co. Ltd., em Pequim, na China; e a Sojitz Corporation, em Tóquio, no Japão. Ela dispõe de armazéns de produtos na Suécia, Rússia, Holanda, Itália, Espanha, Canadá, Estados Unidos, China, Coreia do Sul e Japão (CBMM, 2018; 2019).

Dessa maneira, o repertório de ações da CBMM no Brasil e em diversos países e continentes, expõe suas práticas corporativas com a intenção de criar, aumentar e capturar valor (MILANEZ et.al, 2018). Entre as estratégias da CBMM, destaca-se a de mercado, ao atuar por meio de suas subsidiárias responsáveis por programas de comercialização, manutenção de armazéns de produtos e escritórios corporativos em regiões centrais em termos de acesso ao mercado, como a Europa, América do Norte e Ásia.

Ainda no campo de ação estratégica de mercado, a CBMM mantém investimentos e parcerias com os usuários finais dos produtos de nióbio. Conforme destacado por Vasconcelos (2018), um dos exemplos é a colaboração firmada em 2017 com a empresa japonesa Toshiba. A intenção seria elevar a demanda do mercado por óxidos de nióbio usados na fabricação de carros elétricos. Para isso, a CBMM declarou investir US\$ 7,2 milhões na construção de uma unidade-piloto de baterias junto a uma fábrica da Toshiba em Kashiwazaki, no Japão. Nessa fábrica será desenvolvida uma nova geração de baterias com anodos de óxidos mistos de nióbio e titânio (VASCONCELOS, 2018; CBMM, 2018).

Ademais, destaca-se a política de investimentos em pesquisa e desenvolvimento de novos produtos e aplicações do nióbio, o que contribui com sua estratégia de mercado e também social. Para isso, ela mantém um Centro de Tecnologia em Araxá, que conta com 130 pesquisadores e técnicos envolvidos em 30 projetos de inovação tecnológica ligada às aplicações do nióbio. Em 2017, a CBMM investiu cerca de R \$ 150 milhões no desenvolvimento de novos processos tecnológicos, aplicações e mercados do nióbio 
$(\text { CBMM, 2018 })^{2}$. Naquele ano, ela somou 179 projetos de cooperação técnica em andamento no mundo, sendo 137 parcerias com clientes, 27 com universidades e 15 com institutos de pesquisa (CBMM, 2019). Ela ainda inaugurou em Xian, na China, um novo centro de tecnologia, o International Welding Technology Center (CBMM, 2019; VASCONCELOS, 2018).

A opção pelo desenvolvimento tecnológico dos usos do nióbio se mostra como uma estratégia de criação de mercado que vem sendo desenvolvida historicamente pela CBMM. Desde os anos 1970, a empresa promove e participa de simpósios, palestras, seminários e publicações de trabalhos técnicos e científicos com o propósito de disseminar tecnologias do nióbio nos mercados efetivos ou promissores. Em 1979, foi criado o prêmio Charles Hatchett, patrocinado pela CBMM e concedido pelo Institute of Materials, Minerals and Mining (IOM3), em Londres, aos autores que se sobressaem com trabalhos de pesquisas publicados sobre ciência e a tecnologia do nióbio e suas ligas. Também organizado pela IOM3, a CBMM participa, com início em 2011, do patrocínio do Young Persons' World Lecture Competition (YPWLC), um concurso criado em 2005 que abrange a participação de jovens cientistas de diversos países (CBMM, 2018; 2019). Assim, de acordo com as prioridades estratégicas da CBMM, os recursos gerados pela extração mineral no Brasil são utilizados, em grande parte, para o subsídio e o estímulo do desenvolvimento tecnológico em outros países.

Dessa forma, a CBMM parece ter uma clara política para o desenvolvimento do mercado internacional para o minério extraído no Brasil. Apesar de focar sua atuação na extração e beneficiamento intermediário de nióbio, a empresa demonstra uma preocupação em garantia da expansão da demanda pelo desenvolvimento de novos usos. Essa postura se concretiza na diversificação de produtos, uma vez que ela é a única empresa no país que beneficia o nióbio em todas as duas variações (liga de ferro-nióbio, liga de grau-vácuo, nióbio metálico e óxido de nióbio), enquanto as demais se concentram na produção de ferro-nióbio (VASCONCELOS, 2018; PEREIRA JÚNIOR, 2010; CBMM, 2019).

Esse posicionamento define uma estratégia bastante diferente daquela, aparentemente, adotada pela CMOC. O posicionamento da empresa chinesa em Goiás mostra outra estratégia, como será visto na próxima seção.

\section{Goiás e a Rede Global Extrativa de nióbio}

\section{Megamineração em Goiás}

Goiás ocupa a terceira posição - depois de Minas Gerais e Pará - entre os principais territórios de extrativismo mineral no Brasil, conforme o valor das operações minerais que aumentaram de $\mathrm{R} \$ 1,1$ bilhão em 2005 para $\mathrm{R} \$$ 4,9 bilhões em 2018, um

\footnotetext{
2 "Em virtude dos projetos de tecnologia desenvolvidos, a CBMM desfruta desde 2007 de um benefício fiscal federal, concedido com base na Lei de Incentivo a Inovação (11.196/2005): o benefício acumulado até 2017 foi de cerca de R\$ 57 milhões" (CBMM, 2018, p. 28).
} 
crescimento de 372,6\%. Da mesma maneira, de acordo com os valores da arrecadação da Compensação Financeira pela Exploração de Recursos Minerais (CFEM), que saltou de $\mathrm{R}$ \$ 15,2 milhões em 2005 para R \$ 98,7 milhões em 2018, uma evolução de 547,3\% (ANM, 2006; 2018).

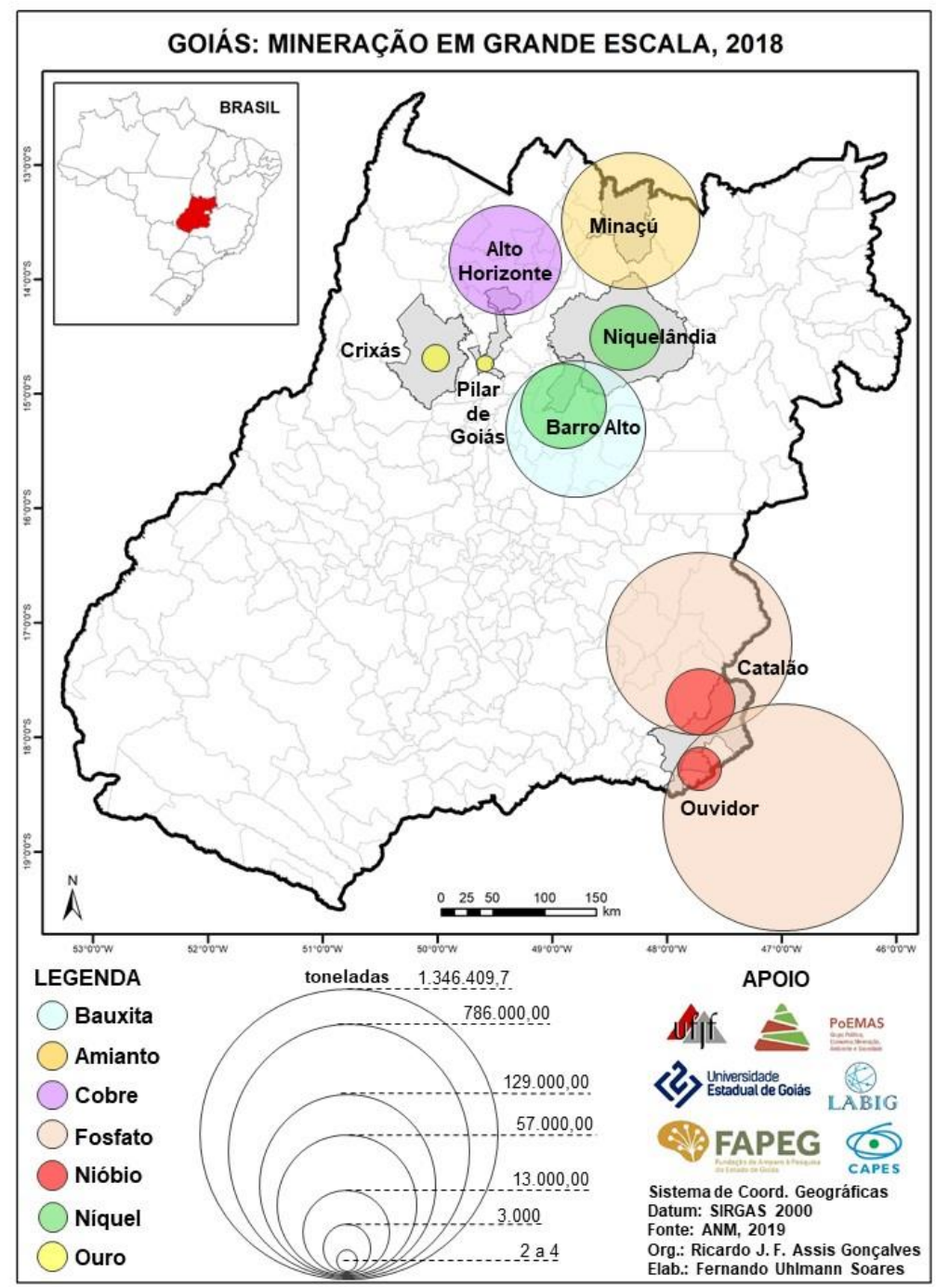

Figura 04: Principais municípios minerados em Goiás.

Diante disso, Goiás presenciou também o crescimento dos valores da produção mineral, que subiu de $\mathrm{R}$ \$ 2,7 bilhões em 2005 para R \$ 9,3 bilhões em 2017, uma ampliação 
de 234,2\% (ANM, 2006; 2018). No entanto, esses valores concentram-se em poucos municípios minerados e em um número reduzidos de minérios explotados. Em 2017, das 32 substâncias minerais que compuseram o valor da produção mineral, apenas nove responderam por $\mathrm{R} \$ 9,1$ bilhões, o equivalente a 97,7\% do total, sendo elas: cobre, níquel, ouro, fosfato, nióbio, amianto, calcário agrícola, brita e água mineral. Ainda no mesmo ano, de uma sequência de 141 municípios que contribuíram com o valor da produção mineral no estado, apenas Alto Horizonte, Niquelândia, Catalão, Ouvidor, Minaçu, Crixás, Barro Alto e Pilar de Goiás, responderam por $\mathrm{R} \$ 8,7$ bilhões, o equivalente a aproximadamente $92 \%$ do valor total (ANM, 2018). Assim, a concentração da renda mineral se torna uma das principais características da atividade no estado.

Por consequência, esses dados e informações certificam a legenda espacial da mineração em grande escala em Goiás (Figura 04).

A legenda espacial da mineração em grande escala em Goiás, ilustrada na Figura 04, além de identificar a localização dos principais projetos de extração mineral no norte e sudeste goianos, permite refletir sobre a integração do estado e dos municípios minerados com as redes globais extrativas. Por exemplo, no ano de 2018, o ouro extraído de municípios como Crixás foi exportado para o Reino Unido, Itália, Bélgica, Índia e Emirados Árabes Unidos. O cobre explotado em Alto Horizonte foi vendido para Espanha, Índia, Bulgária e Cingapura. O níquel (na forma de ferro-níquel) de Barro Alto e de Niquelândia foi comercializado com dezesseis países, e os principais importadores foram China, Holanda, África do Sul, Suécia, Finlândia e Estados Unidos. O amianto extraído em Minaçu foi também vendido para dezesseis países, entre eles a Índia, Indonésia, Malásia, Vietnã e Bangladesh. Por fim, o nióbio (transformado em ferro-nióbio) de Catalão e Ouvidor, foi exportado para 12 países, entre eles a China, Holanda, Estados Unidos, Índia, Cingapura, Coreia do Sul e Turquia (ANM, 2018).

Dessa forma, a perspectiva colocada, ao menos do ponto de vista das corporações mineradoras, é do aprofundamento da dependência da economia goiana da exportação de bens minerais.

\section{Megaprojetos extrativos de nióbio}

A territorialização dos empreendimentos de mineração e beneficiamento de nióbio em Catalão e Ouvidor é fundamental na relação de Goiás com as Redes Globais Extrativas. Ela perpassa o processo de internacionalização do território goiano a contar da década de 1970 diante da expansão dos megaprojetos de extrativismos agrominerais. Desse modo, Carvalho (1988) e Ferreira Neto (1998) explicam que as jazidas de pirocloro identificadas pela Metais de Goiás SA (METAGO) em Catalão e Ouvidor motivaram a criação da Mineração Catalão de Goiás S.A, controlada pela corporação Sul Africana Anglo American, que iniciou trabalhos de pesquisas no início dos anos 1970.

Com a constatação da viabilidade do projeto, iniciou-se a abertura de uma mina a céu aberto no Chapadão (entre Catalão e Ouvidor) e a construção de uma usina de 
concentração de pirocloro, a Planta de Concentração Boa Vista, no município de Ouvidor. Na mesma década, a Mineração Catalão de Goiás S.A iniciou os processos de extração e processamento do nióbio na produção da liga de ferro-nióbio. Além disso, essa empresa foi a primeira de capital privado a explorar os depósitos minerais do Complexo AlcalinoCarbonatitico de Catalão (CARVALHO, 1988; FERREIRA NETO, 1998).

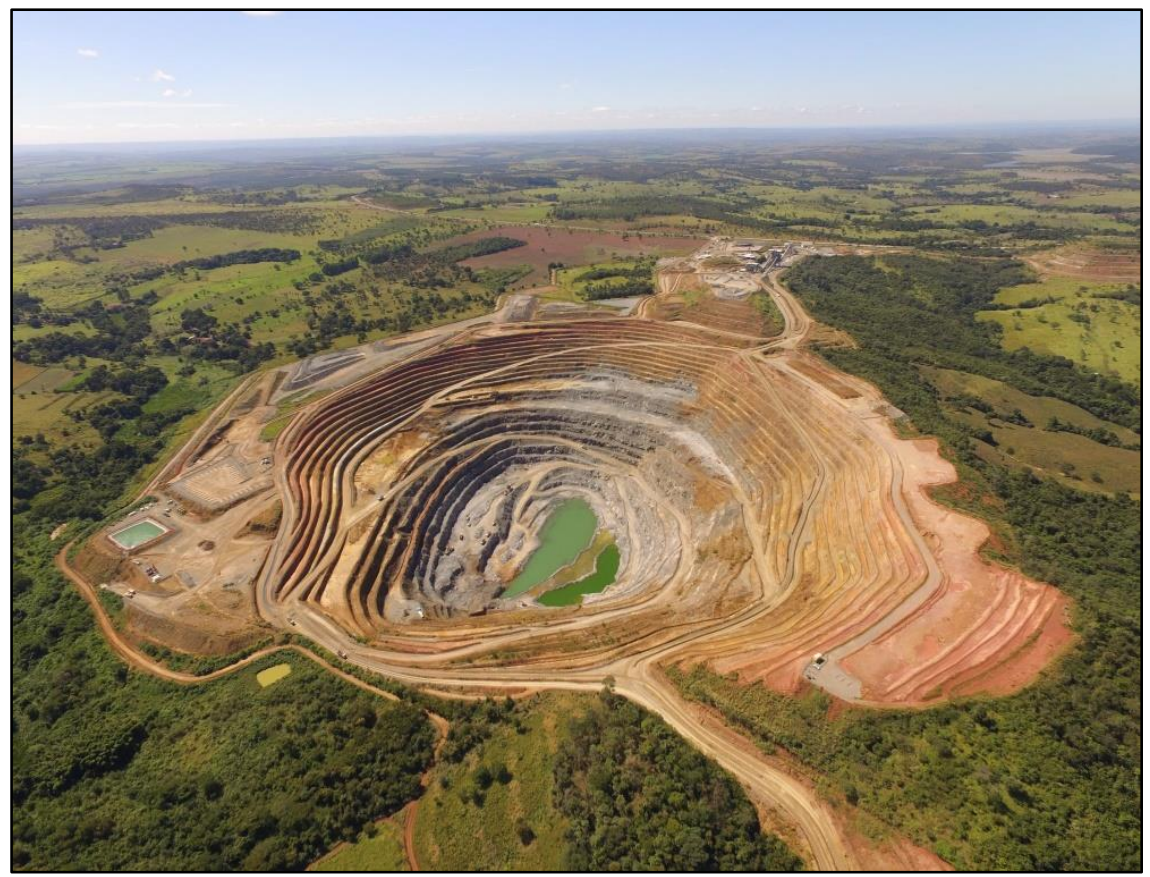

Figura 05: Mina Boa Vista, Catalão, Goiás.

Fonte: ANM, 2017.

À vista disso, em 1976, a produção de ferro-nióbio registrada em Goiás foi de 773 toneladas; em 1980 atingiu 3.517 toneladas e desde então, até o início dos anos 2000, manteve relativa estabilidade do percentual produtivo. Nos primeiros anos do século XXI foram realizados novos investimentos e expansão dos projetos de extração e transformação do nióbio ainda operados pela Anglo American. Entre eles, uma nova mina a céu aberto, a Mina Boa Vista, em Catalão. Sendo assim, o início da extração de minério na Mina Boa Vista no ano de 2000 (Figura 05), se deu com a intenção de suprir a Planta de Concentração Boa Vista.

Ainda no decorrer da década de 2000 e diante da conjuntura de aumento da demanda mundial pelo metal, a então Mineração Catalão executou o Projeto Tailings, aprovado em 2006 e concluído em 2008. O Projeto contou com investimentos de US\$ 30 milhões e propiciou o início da recuperação do nióbio contido nos rejeitos dos processos 
de beneficiamento de fosfato pela Copebrás (também empresa da Anglo American naquele momento, 2008) para a produção de ferro-nióbio (SILVA et.al, 2017).

Quatro anos depois da conclusão do Projeto Tailings, em 2012, a Anglo American voltou a investir em um novo projeto chamado Boa Vista Fresh Rock (BVFR), focado na extração e beneficiamento do nióbio contido em rocha fresca, devido à exaustão do minério oxidado prevista para 2016 (SILVA et. al., 2017). O Projeto BVFR foi concluído em 2014 e contou com investimentos de aproximadamente US\$ 350 milhões. Silva et. al (2017) acentuam que o BVFR propiciou o aumento da vida útil da mina (Life of Mine) e do negócio de nióbio em Catalão e Ouvidor próximo a 20 anos, além de capacitar os empreendimentos para triplicar a produção da liga de ferro-nióbio no decorrer dos anos.

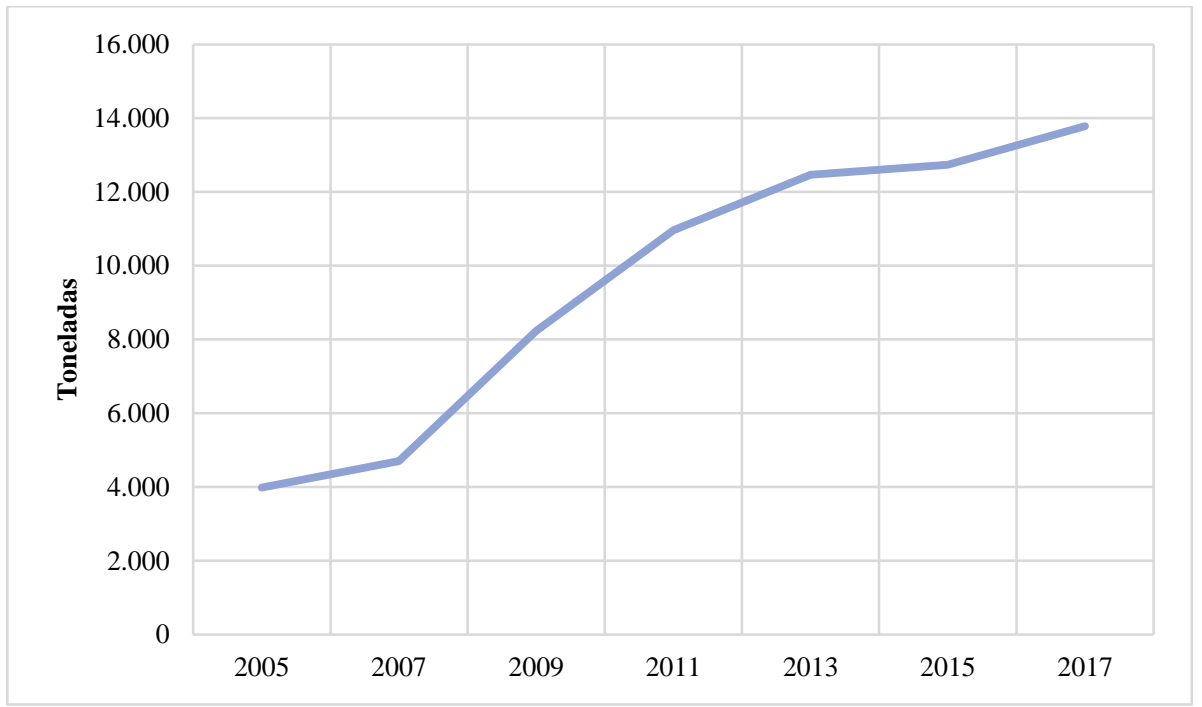

Figura 06: Evolução da produção de ferro-nióbio em Goiás no período de 2005 a 2017. Fonte: ANM, 2018. Elaboração: GONÇALVES, R. J. A. F.; MILANEZ, B., 2019.

Por consequência, desde meados dos anos 2000, com a Mina Boa Vista, em Catalão, a unidade de beneficiamento e metalurgia Boa Vista, o projeto Tailings e o projeto BVFR em Ouvidor, as cifras de produção de ferro-nióbio cresceram de maneira significativa de 2005 a 2017, conforme apresentado na Figura 06.

A produção de ferro-nióbio em Goiás cresceu de 3,9 mil toneladas em 2005 para 13,7 mil toneladas em 2017, um aumento de $245,8 \%$. Nesse sentido, a observação da Figura 06 auxilia no entendimento da relação entre a evolução dos números de toneladas de ferro-nióbio produzido em Goiás com os principais projetos e investimentos no decorrer do período analisado. Destarte, primeiro distingue-se o crescimento de 2005 a 2009, de 3,9 mil toneladas para 8,2 mil toneladas respectivamente, uma ascensão de 106,3\% . Esse momento coincide com a expansão da Mina Boa Vista e a conclusão do 
Projeto Tailings. Segundo, observa-se que a partir de 2010, a tendência de crescimento foi significativa, atingindo o maior nível em 2016, quando a produção alcançou 15 mil toneladas, $141,2 \%$ a mais se comparado com 2010. O crescimento nesse segundo intervalo, 2010 a 2016, foram concomitantes com dois aspectos principais: a implementação do Projeto BVFR e a entrada do capital chinês nos negócios de nióbio em Goiás com a compra dos negócios da Anglo American pela CMOC International Brasil, em 2016.

Assim, frente ao aumento assinalado pelas novas escalas de produção de nióbio em Goiás, constata-se a relação desse processo com o incremento das exportações de ferro-nióbio e o fortalecimento da sua participação na rede global (Figura 07).

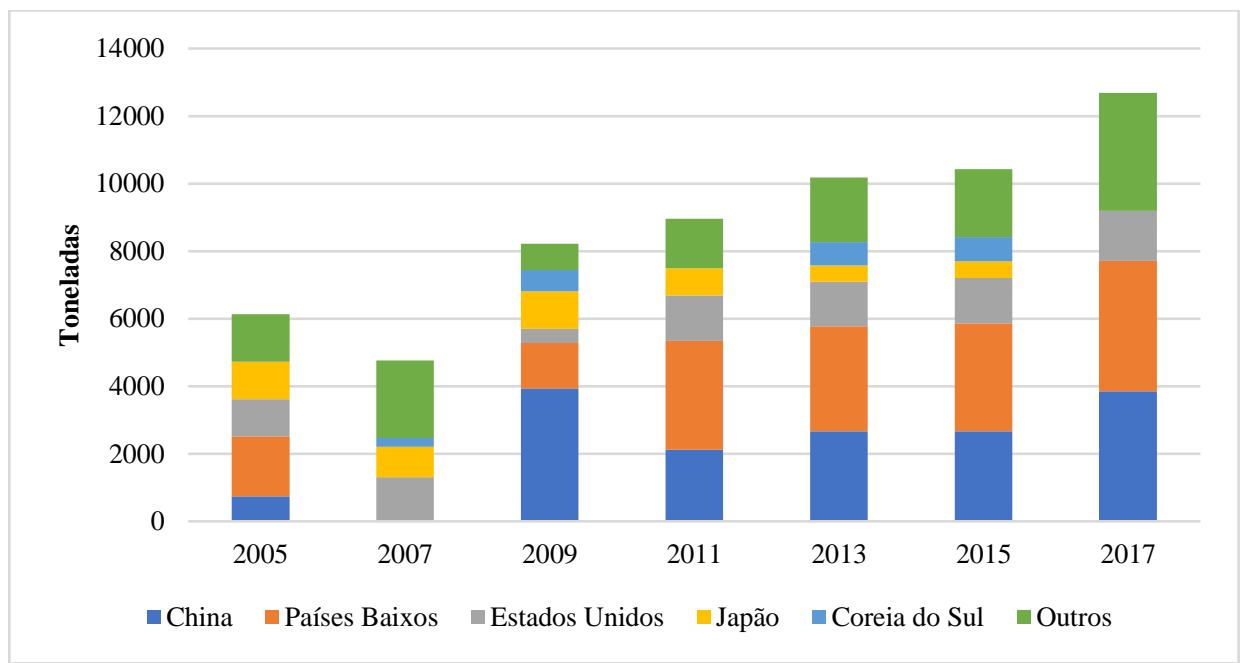

Figura 07: Evolução das exportações goianas de ferro-nióbio de acordo com os principais países importadores - 2005 a 2017.

Fonte: ANM, 2018. Elaboração: GONÇALVES, R. J. A. F.; MILANEZ, B., 2019.

A Figura 07 sublinha o desempenho das exportações da liga de ferro-nióbio produzida em Goiás para cinco dos principais países importadores no intervalo de 2005 a 2017. No decorrer dos treze anos, o estado exportou 108,9 mil toneladas de ferro-nióbio. Desse total, apenas os cinco países destacados compraram 86,3 mil toneladas da liga, o equivalente a 79,2\%. Dois deles, China e os Países Baixos, aumentaram as escalas de suas compras e importaram cerca de metade do total extraído, 54 mil toneladas. Os demais, com exceção do Japão, que diminuiu sua participação nas importações a partir de 2010, sustentaram taxas de compras relativamente estáveis. Ainda, em 2005, 2006 e 2007, além dos cinco países destacados, Goiás teve a Alemanha como principal rota internacional, que importou, em média, 2 mil toneladas (ANM, 2018).

Ao se considerar as mudanças na estrutura de propriedades no setor, um episódio de grande relevância foi a compra dos negócios de fosfato (Copebrás, em Goiás e São 
Paulo) e nióbio (Mineração Catalão, em Goiás) da Anglo American pela China Molybdenum (CMOC), através de sua subsidiária CMOC International Brasil, por US\$ 1,7 bilhão em 2016. Consequentemente, a CMOC criou a Niobras, que a partir de 2016 passou a operar os empreendimentos de mina e metalurgia do nióbio em Catalão e Ouvidor. (CMOC, 2019).

A CMOC é uma empresa com atuação global no setor de mineração, processamento, fundição, tecnologia de produtos, comércio, pesquisa e desenvolvimento mineral. Ela está listada na Bolsa de Valores de Hong Kong e na Bolsa de Valores de Xangai. Na China, ela é proprietária da mina Sandaozhuang, na Província de Henan, onde extrai molibdênio e tungstênio. Além da CMOC International Brasil, que opera os empreendimentos de nióbio e fosfato nos estados de Goiás e São Paulo, a China Molybdenum controla $80 \%$ da Northparkes Mines, uma das maiores produtoras de cobre na Austrália. Também possui participação de quase $60 \%$ da Tenke Fungurume, que opera empreendimentos de cobre e cobalto na República Democrática do Congo. Ainda, destacam-se os seus escritórios corporativos localizados em Phoenix, nos Estados Unidos, e em Sidney na Austrália (STELZER JR., 2016; CMOC, 2019).

A aquisição da Mineração Catalão e a criação da Niobras pela CMOC foi acompanhada por intenso investimento buscando a expansão da extração mineral de nióbio em Goiás. Assim, considerando o total de operações minerais de nióbio no país, a Niobras passou de uma média de $27 \%$ das operações $(2011$ - 2014) para $51 \%$ das operações (2015 - 2018) (ANM, 2019).

Ao mesmo tempo, conforme apresentado na Figura 07, houve um crescimento significativo da participação da China nas importações no final do período estudado. Entre 2007 e 2017, as compras chinesas saltaram de 736 toneladas para 3,8 mil toneladas, uma ampliação de $423 \%$. Assim, no decorrer desses anos ela comprou 28,7 mil toneladas e transformou-se numa das principais interessadas na liga de ferro-nióbio produzida em Goiás.

Além disso, o crescimento da participação chinesa nas importações ganhou força nos últimos anos, coincidindo com sua entrada nos negócios de nióbio em Catalão e Ouvidor. De 2016 a 2017, a China aumentou as importações do ferro-nióbio goiano em cerca de $63 \%$, de 2,3 mil toneladas para 3,8 mil toneladas. Internamente, os efeitos econômicos desse processo também são evidentes, considerando que o valor das operações minerais de nióbio da CMOC no Brasil passou de R \$ 306,2 milhões em 2016 para 369,3 milhões em 2018, um aumento de 20,6\% (ANM, 2019).

Como consequência dessa expansão, o valor total das exportações goianas de ferro-nióbio subiu de US\$ 48,6 milhões em 2005 para US\$ 270 milhões em 2018, o que significou um aumento de 445,5\%. Diante desse aumento, em 2018, entre os produtos da pauta exportadora goiana, o ferro-nióbio foi o sexto mais importante de acordo com o valor das vendas. Entre os bens minerais, foi o terceiro, depois do cobre e do ferro-níquel.

A partir da avaliação do posicionamento da Anglo American (até o início de 2016) e, especialmente, da CMOC, percebe-se um posicionamento estratégico bastante 
diferenciado, quando comparado com a CBMM. Enquanto essa última tem investido no desenvolvimento de usos de maior valor agregado e intensivos em tecnologia do nióbio, mesmo que em outros países, a empresa chinesa, aparentemente, tem como prioridade apenas a expansão da extração de nióbio e da comercialização da liga ferro-nióbio, que possui usos menos nobres. Dependendo dos interesses da China no uso desse metal, existe o risco de que uma expansão muito rápida da extração e exportação. Isso pode gerar desequilíbrios entre oferta e demanda, resultando na redução significativa dos preços, o que, em uma primeira análise, poderia beneficiar principalmente indústrias metalúrgicas chinesas.

\section{Considerações finais}

O presente artigo teve como principal objetivo apresentar a estrutura geral da Rede Global Extrativa do nióbio e analisar, em mais detalhes o seu nó goiano. Dessa forma, buscou-se enfatizar as diferenças no enraizamento em rede e nas estratégias de mercado das principais empresas mineradoras que atuam nessa rede.

Do lado da oferta, a estrutura da rede apresenta um caráter concentrado, de forma que $84 \%$ da extração é realizada no Brasil, onde apenas duas empresas, localizadas em Minas Gerais e Goiás, respondem pela quase totalidade da comercialização dos produtos do metal, especialmente o ferro-nióbio. Ademais, a demanda também apresenta elevado grau de concentração, uma vez que $90 \%$ das exportações são concentradas em cinco países, que dominam tecnologias avançadas da siderurgia e de outros setores intensivos em conhecimento, como equipamentos médicos, ótica e eletrônica.

Apesar de a concentração das reservas no Brasil ter potencial, em teoria, de conferir um maior poder às empresas que atuam no país, tal poder não é necessariamente transformado em ampliação de valor. Assim, a maior parte da exportação nacional se resume a produtos semiacabados (liga ferro-nióbio, nióbio metálico ou óxido de nióbio) que são beneficiados pelos países importadores e transformados em produtos de maior valor agregado. Logo, a rede se estrutura de forma que o Brasil se mantém na periferia da Divisão Internacional do Trabalho.

Nesse sentido, o posicionamento da CBMM se mostra particularmente contraditório ou, ao menos, divergente de uma perspectiva de interesse nacional. A empresa vem desenvolvendo diferentes iniciativas para multiplicar os usos do nióbio, particularmente em países industrializados, como forma de ampliar o mercado consumidor do metal. Todavia, tais inovações, subsidiadas pela renda mineral gerada no país, não são necessariamente incorporadas pelo parque industrial brasileiro. Se, por um lado, tal iniciativa não promove o aumento das atividades de ampliação de valor dentro do país, por outro, ela demonstra sucesso do ponto de vista de captura de valor pela empresa; por exemplo, entre 2017 e 2018, a CBMM aumentou seu lucro em 54,7\%, passando de $\mathrm{R} \$ 1,7$ bilhão para R\$2,8 bilhões (CBMM, 2019). 
A posição de Goiás mostra uma inserção na rede global ainda mais regressiva. Durante o período de operação da Anglo American, não foi identificado nenhum esforço específico de intensificação tecnológica, ou de verticalização da produção. Essa inserção subalterna no mercado global, como mero fornecedor de bens intermediários de baixo valor agregado, aparentemente, se consolidou a partir da entrada da CMOC. Os principais investimentos dessa empresa se restringiram a ampliar as atividades extrativas e, os respectivos impactos territoriais, disputa pelo subsolo e conflitos com comunidades (GONÇALVES, 2016; PAES, 2019).

Essas constatações da estruturação da rede podem ainda ser associadas a três reflexões particulares, apresentadas de forma preliminar, mas que podem ser aprofundadas em estudos futuros.

Primeiro, há indicações da necessidade de se debaterem de forma estruturada as bases materiais da transição para uma economia de "baixo carbono". Dentro do contexto do enfrentamento da crise climática, uma série de "soluções" tem sido propostas no escopo da modernização da matriz energética global. Todavia, carros elétricos, painéis fotovoltaicos e geradores eólicos dependem fundamentalmente de materiais como nióbio, lítio, tântalo, índio e outros "minerais estratégicos". A expansão desse tipo de solução, porém, mantém necessariamente a dependência de recursos não renováveis e tenderá a levar a uma nova rodada de expansão da fronteira mineral.

Em segundo lugar, a análise da rede do nióbio destaca o papel crucial que vem sendo desempenhado pela China. No caso do nióbio brasileiro, ela se manifesta tanto pela aquisição das minas em Goiás, quanto pela compra de parte das ações da CBMM. A "corrida" da China em busca do controle de bens minerais ao redor do mundo já vem sendo debatida na literatura especializada tanto em uma perspectiva global (KLARE, 2013) quanto na América Latina (IRWIN e GALLAGHER, 2013). Todavia, o tema ainda não parece ter sido estudado de forma aprofundada no contexto brasileiro.

Por fim, o esforço por parte da CBMM para desenvolver novos usos para o nióbio sugere a limitada capacidade do mercado de gerar demanda específica por esse metal. Sendo assim, parece haver uma estreita faixa de equilíbrio entre oferta e demanda que garantem a relativa estabilidade dos preços. Os dados indicam que os principais setores industriais que demandam o metal são devidamente abastecidos pela escala de extração atual. Conforme a CBMM (2019) e o Ibram (2019) a capacidade produtiva das empresas produtoras no mundo é mais de duas vezes maior do que a demanda de mercado. Nesse contexto, ainda existe uma série de novos projetos em implantação em diferentes países. Logo, um aumento significativo da extração de nióbio tenderá a causar, principalmente, uma queda significativa de preços, prejudicando países exportadores e beneficiando, exclusivamente, os consumidores do metal.

Finalmente, a partir de tais análises, argumenta-se que o aprofundamento do conceito de RGPs se mostra um caminho promissor para um melhor entendimento dessa cadeia e abre questões relevantes para pesquisas futuras. 


\section{Referências}

ALMG. Gestão do nióbio de Araxá é questionada em audiência. 2019. Disponível em: < https://www.almg.gov.br/acompanhe/noticias/arquivos/2019/04/17_comissao_minas_energia _niobio_araxa.html>. Acesso em: 10 de maio de 2019.

ANM - Agência Nacional de Mineração. Sumário mineral 2005. Brasília/DF: Ministério de Minas e Energia, 2006.

ANM - Agência Nacional de Mineração. Desempenho do setor mineral: Goiás e Distrito Federal. DNPM - 6 DS/GO, 2006.

ANM - Agência Nacional de Mineração. Desempenho do setor mineral: Goiás e Distrito Federal. DNPM - 6º DS/GO, 2009.

ANM - Agência Nacional de Mineração. Desempenho do setor mineral: Goiás e Distrito Federal. DNPM - $6^{\circ}$ DS/GO, 2017.

ANM - Agência Nacional de Mineração. Desempenho do setor mineral: Goiás e Distrito Federal. DNPM - 6º DS/GO, 2018.

ANM - Agência Nacional de Mineração. Maiores arrecadadores CFEM. 2019. Disponível em: <https://sistemas.dnpm.gov.br/arrecadacao/extra/Relatorios/arrecadacao_cfem.aspx>. Acesso em: 20 Fev 2019.

CARVALHO, W. T. de. Política Mineral Goiana (1960 - 1986). Dissertação (Mestrado em Geociências) - Instituto de Geociências, Universidade Estadual de Campinas, 1988.

CARVALHO, A. M. P. de.; MILANEZ, B.; GUERRA, E. C. Rentismo-neoextrativismo: a inserção dependente do Brasil nos percursos do capitalismo mundializado (1990-2017). In: RIGOTTO, R.; A. C. P. A.; RIBEIRO, L. A. D. Tramas para a justiça ambiental: diálogo de saberes e práxis emancipatórias. Fortaleza: Edições UFC, 2018.

CBMM. Relatório de sustentabilidade 2018. Araxá/MG: CBMM, 2019.

CBMM. Relatório de sustentabilidade 2017. Araxá/MG: CBMM, 2018.

CBMM. Nota da CBMM. 2019. Disponível em: <https://g1.globo.com>. Acesso em: 10 de maio de 2019.

CMOC. Negócios - Niobras. Disponível em: http://cmocbrasil.com/br>. Acesso em: 09 de julho de 2019.

G1 Triângulo Mineiro. Ex-presidente da Codemig denuncia problemas na gestão da exploração de nióbio em Araxá. 2019. Disponível em: <https://g1.globo.com>. Acesso em: 10 de maio de 2019.

FERREIRA NETO, M. C. Política, razão e desrazão: dimensões políticas e históricas do Insucesso do Pólo Mínero-Industrial de Catalão/Ouvidor (1962-1992). Dissertação (mestrado em História), Universidade Estadual de Campinas, Campinas, 1998.

GONÇALVES, R. J. A. F. No horizonte, a exaustão: disputas pelo subsolo e efeitos socioespaciais dos grandes projetos de mineração em Goiás. 504f. Tese (Doutorado em 
Geografia) - Universidade Federal de Goiás, Programa de Pós-graduação em Geografia, 2016.

HENDERSON, J. et al. Global Production Networks and the Analysis of Economic Development. Review of International Political Economy, 9: p. 436-464, 2002.

HARVEY, D. A loucura da razão capitalista: Marx e o capital no século XXI. Tradução de Artur Renzo. São Paulo: Boitempo, 2018.

HESS, M. Global Production Networks: dealing with diversity. In: TACHIKI, Dennis; HAAK, René (Eds.). Regional strategies in a global economy: multinational corporations in East Asia. Munich: Iudicium, 2004.

IBRAM. Mineração Taboca dobra produção de nióbio e tântalo no Amazonas. 2016. Disponível em: 〈http://www.ibram.org.br/150/15001002.asp?ttCD_CHAVE=262387>. Acesso em: 10 de Maio de 2019.

IBRAM. Panorama do nióbio: mercado, reservas e produção. In: Seminário Liderança Brasileira na Cadeia do Nióbio. Brasília/DF: MME, 2019.

IBRAM. Eleições 2018: políticas públicas para a indústria mineral. Brasília/DF: Ibram, 2018. IRWIN, A.; GALLAGHER, K. P. (2013). Chinese mining in Latin America: A comparative perspective. The Journal of Environment \& Development, v. 22, n. 2, p. 207-234, 2013.

KLARE, M. T. The race for what's left: the global scramble for the world's last resources. New York: Macmillan. 2012.

MDIC. Séries históricas. Ministério da Indústria, Comércio Exterior e Serviços, 2019. Disponível em: 〈http://www.mdic.gov.br〉. Acesso em: 25 de junho de 2019.

MILANEZ. B. et.al. A Estratégia Corporativa da Vale S.A.: um modelo analítico para Redes Globais Extrativas. Versos - Textos para Discussão PoEMAS, 2(2), 1-43, 2018.

MILANEZ, B. et al. Minas não há mais: avaliação dos aspectos econômicos e institucionais do desastre da Vale na bacia do rio Paraopeba. Versos - Textos para Discussão PoEMAS, 3(1), 1-114, 2019.

NOTÍCIAS DE MINERAÇÃO. CMOC apresenta projeto para investir $R \$ 1,2$ bilhão em Goiás. Disponível em: https://www.noticiasdemineracao.com/tag/cmoc/. Acesso em: 23 de agosto de 2019.

PAES, C. de F. O nióbio e seu impacto silencioso no Brasil. 2019. Disponível em: https://dialogochino.net/25605-niobiums-silent-impact-in-brazil/. Acesso em: 13 de agosto de 2019.

PEREIRA JUNIOR R.F. 2014. Nióbio. In: Lima T.M. \& Neves C.A.R. (Org.). Sumário Mineral 2010. Brasília, Departamento Nacional de Produção Mineral (DNPM), 2010.

RIBEIRO, I. CBMM investe em Araxá para garantir demanda de nióbio. 2019. Disponível em: < https://www.valor.com.br>. Acesso em: 10 de Maio de 2019. 
SILVA, J. D. da. et. al. Produção de nióbio a partir do beneficiamento de Rocha Fresca Da Mina Boa Vista. In... Anais, $18^{\circ}$ Simpósio de Mineração, da ABM Week, São Paulo/SP, 2017.

TRADE MAP. 2019. Disponível em: <https://www.trademap.org/brazil/index.aspx>. Acesso em: 15 de julho de 2019.

SANTOS, R. S. P. dos.; MILANEZ, B. The Global Production Network for iron ore: materiality, corporate strategies, and social contestation in Brazil. The Extractive Industries and Society, V. 2, p. 756-765, $2015 \mathrm{~b}$.

STELZER JR., M. A. Um economista brasileiro no alto comando chinês. Revista In The Mine, Nov/Dez, 2016.

VASCONCELOS, Y. A polêmica do nióbio. Pesquisa Fapesp, São Paulo, v.277, p.65-29, 2019.

Agradecemos o apoio da CAPES e da FAPEG pela bolsa de estudos no âmbito do estágio de Pós-Doutorado realizado no Programa de Pós-Graduação em Geografia da Universidade Federal de Juiz de Fora (UFJF). Agradecemos também ao Prof. Fernando Uhlmann Soares pelo apoio na elaboração dos mapas.

\section{Ricardo Junior de Assis Fernandes Gonçalves}

Doutor em Geografia pela Universidade Federal de Goiás (UFG). Professor dos cursos de Graduação e Pós-Graduação em Geografia da Universidade Estadual de Goiás (UEG). Pesquisador do Grupo de pesquisa e extensão Política, Economia, Mineração, Ambiente e Sociedade (PoEMAS).

R Antônio Poteiro, 10999 QD 08 BL 05 APT 203, Setor Goiânia 2, CEP: 74665-080

Goiânia-GO.

E-mail: ricardo.goncalves@ueg.br

\section{Bruno Milanez}

Doutor em Política ambiental pela Lincoln University, Nova Zelândia. Professor do Programa de Pós-Graduação em Geografia e no Departamento de Engenharia de Produção e Mecânica da Universidade Federal de Juiz de Fora (UFJF).

Pesquisador do Grupo de pesquisa e extensão Política, Economia, Mineração, Ambiente e Sociedade (PoEMAS).

Departamento de Engenharia de Produção e Mecânica, Faculdade de Engenharia, Universidade Federal de Juiz de Fora. Rua José Lourenço Kelmer, s/n, São Pedro, CEP: 36036-900, Juiz de Fora, MG.

E-mail: bruno.milanez@ufjf.edu.br 